\title{
QUALIDADE EM MUSEUS: O SENTIMENTO DOS VISITANTES DO ECOMUSEU DE ITAIPU
}

\author{
SERVICE QUALITY IN MUSEUMS: THE SENTIMENT OF ITAIPU ECOMUSEUM VISITORS
}

\author{
lury Teixeira de Sevilha Gosling \\ Universidade Federal de Lavras \\ Doutorando em Administração \\ Lavras, MG, Brasil \\ Email: iurygosling@gmail.com \\ Marlusa de Sevilha Gosling \\ Universidade Federal de Minas Gerais \\ Professora \\ Belo Horizonte, MG, Brasil \\ Email: marlusa@ufmg.br
}

Francis Marcean Resende Barros

Universidade Federal de Minas Gerais

Mestrando em Administração

Belo Horizonte, MG, Brasil

Email: Francis031995@gmail.com

\section{Georgia Caetano}

Universidade Federal de Minas Gerais

Doutoranda em Administração

Belo Horizonte, MG, Brasil

Email: georgiacaetano@hotmail.com

\section{Francisval de Melo Carvalho}

Professor Associado da Universidade Federal de Lavras

Lavras, MG, Brasil

Email: francarv@ufla.br

\section{Daniel Carvalho de Rezende}

Professor Associado da Universidade Federal de Lavras

Lavras, MG, Brasil

Email: danielderezende@ufla.br

\section{RESUMO}

Os museus assumiram novos papéis no contexto da experiência turística, enquanto as mídias sociais permitiram o compartilhamento de informações por meio da internet. Diante disso, este estudo buscou analisar os comentários dos visitantes do Ecomuseu de Itaipu inseridos na plataforma TripAdvisor. A partir do modelo de qualidade percebida em museus, os dados foram submetidos à análise de conteúdo e análise de sentimento. Os principais resultados mostram que os aspectos relacionados às dimensões de evidência física e qualidade da informação são os mais mencionados. Além disso, o sentimento dos usuários é majoritariamente positivo em todas as dimensões. Para a área, o estudo contribuiu ao reunir os elementos da análise de sentimento à análise de conteúdo de forma a graduar as informações de maneira mais precisa e imparcial. Gerencialmente, reforça-se a necessidade de atenção da empresa aos aspectos tangíveis do ecomuseu, bem como se oferece um insight para a incorporação de elementos que causem impacto positivo no sentimento dos visitantes.

Palavras-chave: Qualidade. Serviço. Museus. Análise de sentimento.

\begin{abstract}
Museums began to take new roles in tourism experience context, while social media has enabled the information sharing through the internet. Considering this, this study aimed to analyze the comments of the Itaipu Ecomuseum visitors inserted in the TripAdvisor platform. Based on the model of perceived quality in museums, the data were submitted to content analysis and sentiment analysis. The main results showed that the aspects related to the dimensions of physical evidence and quality of information are the most mentioned. In addition, user sentiment is mostly positive in all dimensions. Thus, the study contributed by bringing the elements of sentiment analysis into content analysis in order to classify information more accurately and impartially. In managerial terms, the company's need for attention to the tangible aspects of the ecomuseum is reinforced, as well as an insight to the incorporation of elements that have a positive impact on the visitors' feeling is given.
\end{abstract}

Keywords: Quality. Service. Museums. Sentiment analysis. 


\section{INTRODUÇÃO}

Os museus se configuram como os atrativos mais importantes quando a motivação da viagem é o turismo cultural, representando mais de 50\% de todas as visitações (RICHARDS, 2007). Esses equipamentos têm sido contemplados com a economia proveniente do turismo, devido, entre outros motivos, às estratégias de marketing das cidades, o que, consequentemente, resultou em uma "turistificação dos museus" (ALCARAZ; HUME; MORT, 2009). Contudo, atualmente, os gestores têm direcionado o foco para além das curadorias e exposições, com artefatos e instalações tangíveis, para elementos intangíveis, como a qualidade das experiências dos visitantes e dos turistas (SU; TENG, 2018).

Muitas das vezes, a movimentação de pessoas em museus implica longas filas, barulho e superlotação, fatores que comprometem a atmosfera reverencial tradicional e podem causar interferência e frustração aos turistas em férias bem como aos frequentadores habituais. Portanto, a capacidade de recepção dos museus ainda é uma questão desafiadora, o que tem, segundo Su e Teng (2018), impactado em suas operações.

Nas últimas décadas, muito além de apenas contar o número de visitas, os museus têm procurado entender melhor quem são e como se comportam os seus visitantes. Dependendo da avaliação global da experiência, os visitantes podem ser surpreendidos tanto negativa como positivamente em suas experiências de visitação (TUNG; RITCHIE, 2011). E, ainda, com o advento das mídias sociais, os turistas começaram a avaliar suas experiências por museus em plataformas baseadas na web, que também são exploradas pelos viajantes para inspiração e planejamento de viagens.

No âmbito da internet, o TripAdvisor se destaca como a maior rede on-line de consumidores de viagens. $\mathrm{Na}$ plataforma, os consumidores podem acessar o site e consultar opiniões quantitativas e qualitativas sobre qualquer hotel, restaurante ou outra atração de viagem ao redor do mundo, todas postadas por outros viajantes. Por meio da plataforma, pode-se recomendar ou não o item avaliado. Além disso, é oferecida a oportunidade de compartilhar fotos e vídeos espontâneos para dar suporte aos comentários postados (O'CONNOR, 2010).

Diante do exposto, este estudo objetivou analisar os comentários inseridos pelos visitantes do Ecomuseu de Itaipu no site TripAdvisor, considerando as quatro dimensões da qualidade de serviços em museu: tangíveis, qualidade da informação, comunicação e atendimento (GOSLING et al., 2016).

Destaca-se, neste estudo, que a insatisfação é valiosa para medir e identificar serviços inadequados de museus e criar oportunidades de melhoria para eles (TAX; BROWN, 1998). Assim, as implicações práticas e gerenciais deste trabalho podem contribuir para que gestores públicos e privados dos equipamentos museográficos possam proporcionar melhores serviços e melhor experiência para seus visitantes.

\section{FUNDAMENTAÇÃO TEÓRICA}

O serviço é caracterizado como uma atividade econômica realizada entre um prestador e um cliente. Clientes trocam dinheiro pela obtenção de valor, habilidades, conhecimentos, bem como o acesso a bens, redes e sistemas. Por sua característica essencialmente intangível, destaca-se que a utilização de um serviço não fornece a propriedade, além de ter sua avaliação significativamente dificultada em relação à avaliação dos bens (WIRTZ; LOVELOCK, 2018).

Dentre os construtos relacionados aos serviços, destaca-se a qualidade, que pode ser entendida como um reflexo da percepção dos clientes levando em conta os aspectos tangíveis do serviço, bem como a empatia, responsividade, segurança e confiabilidade envolvidas na prestação do serviço (ZEITHAML; BITNER; GREMLER, 2014). A gestão da 
qualidade, portanto, é essencial no sentido de mantê-la em níveis elevados para o cliente, dado que ela impacta em comportamentos importantes do consumidor, como a recompra e a publicidade boca-a-boca (WIRTZ; LOVELOCK, 2018).

Adotar um sistema de gestão da qualidade no segmento turístico é uma decisão estratégica que implica vantagens no longo prazo, a saber, a diminuição dos custos, o reforço da responsabilidade e da satisfação dos funcionários com relação ao seu trabalho e o aumento da satisfação do cliente (ALBU, 2009). Assim, a percepção da qualidade de um serviço por parte do cliente amplia a satisfação do cliente, aperfeiçoa a formação de imagem e promove o desenvolvimento do serviço. No turismo, sobretudo, isso é intensificado, tendo em vista que os serviços relacionados a esse segmento são altamente experienciais (MONDO; SILVA; MARTINS, 2016).

\section{Qualidade do serviço em museus}

Desde a década de 1980, entregar uma qualidade de serviço superior era considerado um importante pré-requisito para o sucesso e até mesmo para a sobrevivência dos negócios (PARASURAMAN; ZEITHAML; BERRY, 1988). Assim, diante da dificuldade de se mensurar o construto, Parasuraman et al. (1988) propuseram uma escala para mensuração da qualidade em cinco dimensões (Quadro 1).

Quadro 1 - Dimensões da qualidade

\begin{tabular}{|l|l|}
\hline \multicolumn{1}{|c|}{ Dimensão } & \multicolumn{1}{c|}{ Descrição } \\
\hline Aspectos tangíveis & Aparência dos equipamentos, funcionários e materiais envolvidos na prestação do serviço. \\
\hline Confiabilidade & Capacidade de execução do serviço prometido de forma confiável e correta. \\
\hline Responsividade & Disponibilidade para atender as necessidades dos clientes e prestar um serviço rápido. \\
\hline Segurança & Capacidade de transmitir confiança aos clientes. \\
\hline Empatia & Atenção individualizada dispendida no atendimento. \\
\hline
\end{tabular}

Fonte: Parasuraman, Zeithaml e Berry (1988).

O modelo, conhecido como SERVQUAL, representa um esqueleto básico para a avaliação da qualidade da prestação do serviço por meio de cinco dimensões. A qualidade do serviço reflete uma avaliação com base na percepção do cliente em relação à confiabilidade, a segurança, a responsividade, a empatia e os aspectos tangíveis da prestação do serviço, tendo papel influenciar em construtos mais amplos, como a satisfação (ZEITHAML; BITNER; GREMLER, 2014).

O modelo trouxe versatilidade de adaptação em relação a diversos segmentos de serviços, sendo testada e validada em diversos estudos. Em virtude disso, a escala ganhou grande destaque (ROSALEM, 2013). Nos museus, as experiências são cognitivas e afetivas, relacionando-se com os contextos pessoais dos visitantes (FALK; DIERKING, 2016). Dada sua singularidade, Frochot e Hughes (2000) criaram a escala HISTOQUAL como uma adaptação da escala SERVQUAL, abrangendo cinco dimensões.

A HISTOQUAL mantém três dimensões da SERVQUAL, quais sejam, atendimento, tangíveis e empatia, acrescentando a elas as dimensões de comunicação e consumíveis. A comunicação se refere à qualidade da informação histórica provida pelo prestador de serviço, enquanto os consumíveis se relacionam a serviços anexados à prestação, como restaurantes e outras conveniências (FROCHOT; HUGHES, 2000).

A partir desta escala, o estudo realizado por Gosling et al. (2016) validou quatro dimensões da qualidade: qualidade da informação, atendimento, comunicação e aspectos tangíveis. Dentre essas, a análise indicou que a dimensão de tangíveis foi a que apresentou maior variância explicada, mostrando que os aspectos físicos dos museus são muito relevantes na mensuração de sua qualidade. A partir disso, tem-se o modelo conceitual que será utilizado nesse artigo (Figura 1). 
Figura 1 - Modelo conceitual de qualidade em museus

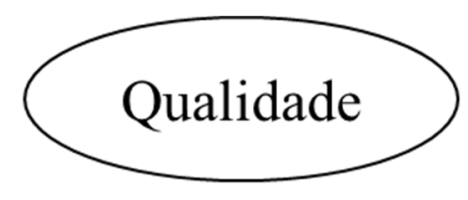

\begin{tabular}{|c|c|c|c|}
\hline Tangíveis & Informação & Comunicação & Atendimento \\
\hline Instalações & Autenticidade & Detalhes & Prontidão \\
\hline $\begin{array}{l}\text { Equipamentos } \\
\text { Funcionários }\end{array}$ & Estímulos & Qualidade histórica & Disponibilidade \\
\hline
\end{tabular}

Fonte: Gosling et al. (2016).

Ainda que a excelência da qualidade seja de suma importância para os negócios, a intenção de fornecer serviços com alta qualidade não é suficiente. Assim, torna-se necessária a adoção, por parte das instituições, de processos estruturados para monitorar a percepção dos clientes com relação à qualidade do serviço prestado. Tais avaliações devem ser contínuas, visto que o cliente sempre pode mudar a direção dos serviços de acordo com suas necessidades (MIGUEL; FREIRE, 2016).

\title{
Conteúdo gerado pelo usuário
}

Com o advento das mídias sociais, turistas começaram a registrar a avaliação de suas experiências em museus em plataformas da internet, como o TripAdvisor. Tais plataformas são relevantes à medida que são cada vez mais consideradas para inspiração e planejamento de viagens (SU; TENG, 2018). Em geral, as declarações positivas ou negativas disponibilizadas pelos usuários de um serviço na internet caracterizam o que é conhecido como conteúdo gerado pelo usuário (HENNIG-THURAU et al., 2004).

De acordo com Krumm, Davies e Narayanaswami (2008), o uso desse conteúdo tem aumentado nos últimos anos, provendo benefícios bilaterais. Nesse modelo, o fornecedor de conteúdo (usuário) tem a sensação de contribuição com a informação gerada para os outros usuários. Os demais consumidores, por sua vez, recebem uma fonte alternativa de informação, representando uma oportunidade de se informar além das vias regulares.

No contexto da viagem turística, Xavier $(2018$, p. 3) aponta que

\begin{abstract}
o uso da tecnologia vem influenciando cada vez mais no processo de decisão durante o planejamento de viagens turísticas. Nesse contexto, o Conteúdo Gerado pelo Usuário (CGU) se tornou um importante auxílio na tomada de decisões dos turistas. Os Comentários de Viagem na Internet (CVI), uma forma de CGU, são uma ferramenta de ajuda nesse processo decisório, e consiste em comentários postados online por turistas, acerca de experiências que os mesmos já vivenciaram em suas viagens, dando autonomia ao consumidor durante o planejamento de viagens.
\end{abstract}

De acordo com Fotis, Buhalis e Rossides (2012), as pessoas estão utilizando informações de CGU em sites para tomar decisões relativas às suas viagens e para construir a sua percepção com relação aos destinos turísticos. De forma geral, os clientes dão preferência a serviços que foram bem percebidos e avaliados por consumidores anteriores (AYEH; AU; LAW, 2013). Assim, diversos empreendimentos ligados ao turismo têm integralizado o CGU como uma estratégia de 
marketing, visto que as opiniões expostas pelos clientes que já utilizaram o serviço transmitem maior confiança para os clientes vindouros (XAVIER, 2018).

\section{PROCEDIMENTOS METODOLÓGICOS}

Esta pesquisa tem finalidade exploratória, realizada a partir de uma abordagem qualitativa. Godoy (1995) define a pesquisa qualitativa como aquela que estuda os seres humanos e suas intrínsecas relações sociais estabelecidas em diferentes ambientes e ainda permite que a imaginação e a criatividade levem os investigadores a propor trabalhos que explorem novos enfoques. O estudo exploratório permite aliar as vantagens de se obter os aspectos qualitativos das informações à possibilidade de quantificá-los posteriormente. Esta associação se dá no nível da complementaridade, o que permite ampliar a compreensão do fenômeno em estudo (PIOVESAN; TEMPORINI, 1995).

A coleta dos dados foi realizada por meio do software WebHarvy, versão 5.0.1.148. Foram levantados todos os comentários em língua portuguesa inseridos no site desde 02 de abril de 2012 até 27 de julho de 2018. Para análise dos dados, foi utilizada a técnica de análise de conteúdo a partir das três etapas recomendadas, a saber, pré-análise, exploração do material e tratamento dos resultados (BARDIN, 2011).

Na pré-análise, os comentários foram organizados em uma planilha, realizando-se uma verificação de possíveis comentários sem conteúdo. Ao todo, foram captados 1057 comentários, excluindo-se apenas um que não apresentava conteúdo, restando 1056 para análise.

Na exploração do material, realizou-se uma leitura flutuante do conteúdo para possibilitar a elaboração dos códigos para categorização, processo que envolve a criação de classes de agrupamento para os recortes (BARDIN, 2011). As categorias de análise consideradas a priori foram as quatro dimensões da qualidade de serviços em museu: tangíveis, qualidade da informação, comunicação e atendimento (GOSLING et al., 2016).

Para isso, optou-se pelo uso do software NVivo, versão 10.0.638.0, que possibilitou, além da categorização em nós de dados, a utilização de outros recursos, como a contagem da frequência de palavras, a criação de nuvens de palavras e a análise de clusters. Foram criadas quatro categorias relacionadas a cada dimensão da qualidade de serviços em museus, tornando possível verificar a dimensão mais presente nos comentários.

No tratamento dos resultados, foram construídas nuvens de palavras que demonstraram quais atributos foram mais visíveis sob o ponto de vista dos visitantes. Além disso, foi feita uma análise de clusters em três formas de agrupamentos, que evidenciou como as categorias se relacionaram.

Dada a dificuldade de se analisar de maneira interpretativa o grande volume de comentários e considerando que a contagem de palavras relacionadas às dimensões não exprime as sensações dos visitantes, i. e., a simples frequência de palavras não demonstra se as percepções são positivas ou negativas, optou-se, como complemento à análise de conteúdo, por ampliar a pesquisa por meio de uma análise de sentimento.

Para isso, utilizou-se a plataforma iFeel, desenvolvida pelo Departamento de Ciência da Computação da Universidade Federal de Minas Gerais (DCC/UFMG). A plataforma realiza a análise utilizando 18 métodos distintos, classificando o sentimento como positivo, negativo ou neutro.

Dentre os métodos, foi escolhido o algoritmo SentiStrenght, comumente utilizado para análise de comentários (GONÇALVES et al., 2013), que gera cargas em uma escala de -1 até 1 , possibilitando a verificação da potência do sentimento nos comentários. Nessa análise, segundo os critérios da plataforma, foram filtrados os comentários com extensão máxima de até 300 caracteres. 


\section{RESULTADOS E DISCUSSÃO}

Após a realização da primeira etapa, em que se obteve 1056 comentários para realização da análise, iniciou-se o processo de categorização. Os comentários foram codificados de acordo com palavras que refletiam cada uma das dimensões da qualidade. A Figura 2 ilustra e descreve, por meio das nuvens de palavras, quais foram os termos sobressaídos nas avaliações em cada dimensão.

Figura 2 - Nuvens de palavras por dimensão

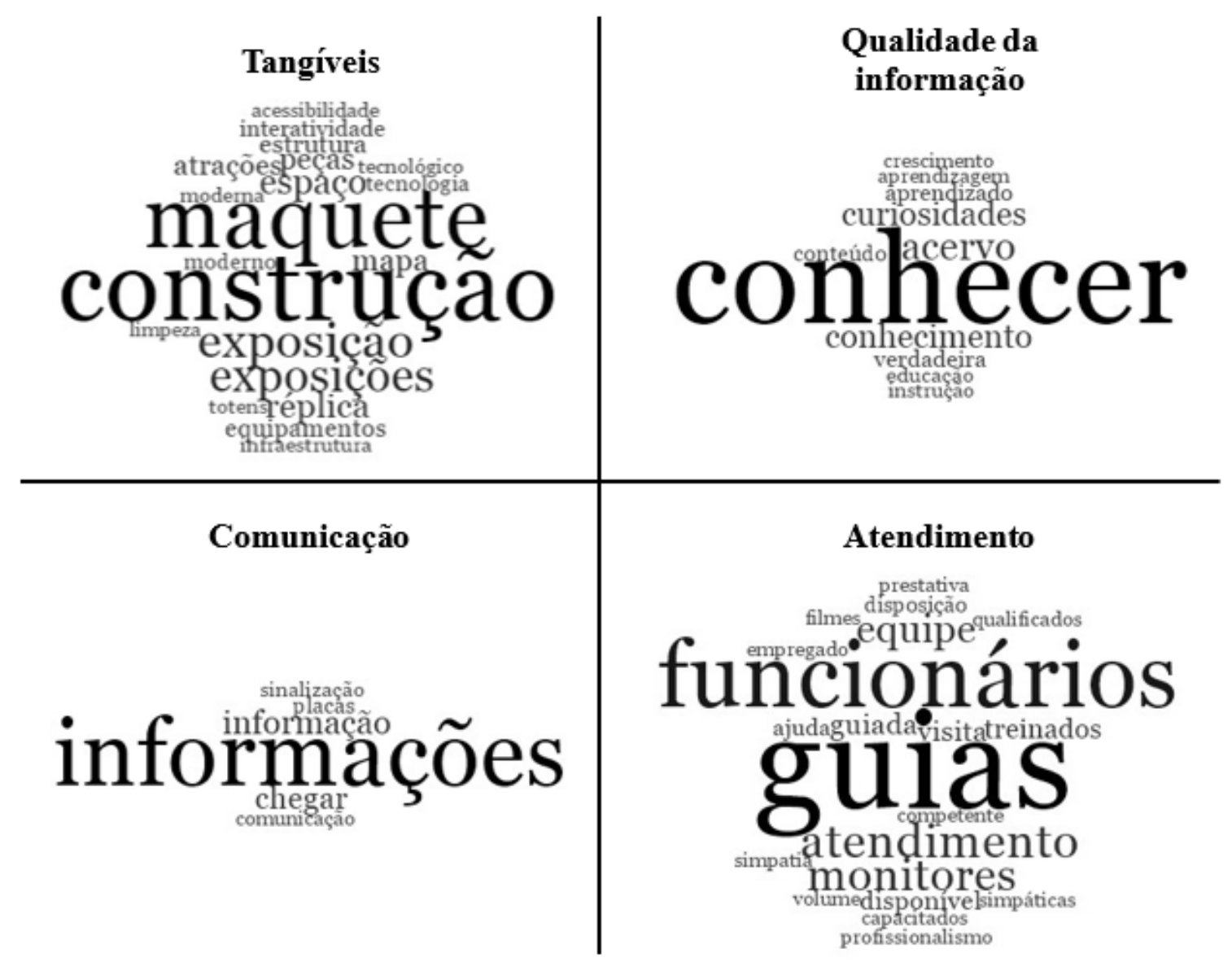

Fonte: saída do software NVivo

Como visto, a avaliação dos serviços é mais difícil de ser realizada se comparada à avaliação de bens físicos (WIRTZ; LOVELOCK, 2018). A partir disso, a percepção dos aspectos tangíveis do serviço é tida como uma grande aproximação para mensurar a qualidade do serviço prestado. 
Evidenciou-se que os termos maquete e construção foram os mais presentes na dimensão tangíveis. Como atestam algumas avaliações, foi considerado que o Ecomuseu "possui interatividade, contém maquetes gigantes mostrado a história da construção da usina, animais nativos empalhados, objetos e quadros a óleo". Sobre as maquetes, ressaltase que o Ecomuseu "tem uma maquete incrível, onde você pode caminhar sobre ela", bem como se considera que "elas são impressionantes e esclarecedoras".

Na dimensão de qualidade da informação, uma das avaliações menciona diretamente o nome da dimensão, demonstrando-se uma surpresa positiva com a "a quantidade e qualidade das informações apresentadas". Já o principal termo foi o conhecer, principalmente no sentido histórico, conforme relatado no trecho a seguir:

Indicado para conhecer a história da Hidrelétrica de Itaipu desde o começo das construções. Um Museu fácil de visitar, rápido, mas surpreendente! As explicações são dadas por ex-barrageiros, onde o amor e emoção de ter participado daquela monumental Usina é estampada na cara.

Na dimensão comunicação, verifica-se a maior frequência do termo informações. O esforço de comunicação é verificado em algumas avaliações de maneiras distintas. Uma avaliação afirma que, na chegada, foram "recepcionados por um monitor, que nos deu algumas informações e nos guiou até a bilheteria", enquanto outra avaliação considera que, no momento da visita, "faltou mais criticidade ao apresentar tais informações".

Na dimensão atendimento, ressaltaram-se os termos "guias" e "funcionários". Diversas avaliações consideraram que o guia é atencioso e tira a dúvida de todos. Por outro lado, aborda-se também que se sentiu falta de "um guia explicando algumas salas".

Para constatar o número de ocorrências, a Tabela 1 resume a contagem de palavras considerando cada uma das dimensões da qualidade de serviço em museus. A quantidade de referências diz respeito à frequência com a qual as palavras relacionadas à dimensão apareceram. Já o número de aparições mede a quantidade de comentários em que pelo menos uma palavra referente à dimensão foi mencionada.

Tabela 1 - Contagem de palavras

\begin{tabular}{lcc}
\hline \multicolumn{1}{c}{ Dimensão } & Quantidade de referências & Número de aparições \\
\hline Tangíveis & 1147 & 646 \\
Qualidade da Informação & 781 & 552 \\
Comunicação & 310 & 242 \\
Atendimento & 212 & 172 \\
\hline & Fonte: elaborado pelos autores
\end{tabular}

Fonte: elaborado pelos autores

As dimensões mais mencionadas foram as de aspectos tangíveis (61\%) e qualidade da informação (52\%). Esse resultado é congruente com o estudo de Gosling et al. (2016), em que a análise demonstrou que as dimensões relativas aos aspectos tangíveis e qualidade da informação foram as que tiveram maior variância explicada. Especificamente, a maior frequência de palavras que refletem a dimensão de aspectos tangíveis corrobora a especificação de Mendonça (2012), que considera a prioridade dos aspectos tangíveis em termos do seu impacto em diversas relações. Na sequência, observa-se as dimensões de comunicação (23\%) e atendimento (16\%). 
Feita a separação dos comentários por dimensão, analisou-se o sentimento dos usuários (Tabela 2). Em termos gerais, o sentimento positivo nos comentários foi mais forte em todas as dimensões. A dimensão de atendimento foi a que teve mais comentários positivos e menos comentários negativos, evidenciando a satisfação dos usuários com o atendimento recebido. Ainda que a dimensão de comunicação tenha apresentado o menor percentual de comentários positivos, verifica-se que eles ainda representam a maioria dos comentários. Além disso, os comentários com sentimento negativo não ultrapassam $10 \%$.

Tabela 2 - Análise de sentimento

\begin{tabular}{lcccc}
\hline \multicolumn{1}{c}{ Dimensão } & Quantidade de comentários & \multicolumn{3}{c}{ Sentimento } \\
& & Positivo (\%) & Negativo (\%) & Neutro (\%) \\
\hline Tangíveis & 462 & $59 \%$ & $10 \%$ & $31 \%$ \\
Qualidade da Informação & 417 & $61 \%$ & $9 \%$ & $30 \%$ \\
Comunicação & 150 & $55 \%$ & $9 \%$ & $36 \%$ \\
Atendimento & 103 & $69 \%$ & $4 \%$ & $27 \%$ \\
\hline
\end{tabular}

Fonte: elaborado pelos autores

A predominância de sentimento positivo é um resultado importante para a gestão do Ecomuseu. Como observado por Mondo, Silva e Martins (2016), a percepção de qualidade amplia a satisfação do cliente, bem como a formação da imagem da própria organização, desenvolvendo seu serviço.

A taxa de comentários neutros, por outro lado, representa uma oportunidade para a gerência do atrativo no sentido de convertê-los para a dimensão positiva. Como sugerido por Miguel e Freire (2016), é recomendável a utilização de processos estruturados e contínuos para acompanhar a evolução da percepção dos clientes, visto que eles interferem na prestação do serviço e podem, em um cenário ruim, transferir suas percepções neutras para percepções negativas.

O acompanhamento deve, perfeitamente, incluir os comentários e fotos inseridos nas redes sociais por parte dos visitantes do Ecomuseu, pois, como verificado por Fotis, Buhalis e Rossides (2012), as pessoas utilizam tais informações como um norte para construção de suas percepções sobre um determinado atrativo turístico.

O Quadro 2 mostra exemplos de comentários com base na carga de sentimento para cada dimensão do estudo. Em alguns casos, não se apresentam as cargas em que não se obteve a presença de comentários. 
Quadro 2 - Comentários por intensidade do sentimento

\begin{tabular}{|c|c|c|}
\hline & Carga & Comentários \\
\hline \multirow{8}{*}{ 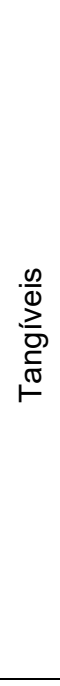 } & 1,00 & $\begin{array}{l}\text { "Excelente!! Conta a história da região, assim como também possui várias maquetes incluindo o período de } \\
\text { construção da Usina!! Possui um piso em vidro sobre um mapa da região, muito interessante!!" }\end{array}$ \\
\hline & 0,75 & "Gostei mais do ecomuseu do que a vista a Usina. Curti muito o mapa no piso de uma das salas. Tirei muitas fotos." \\
\hline & 0,50 & "Interessante para quem gosta de tecnologia e curiosidades. Fomos com crianças e foi super tranquilo." \\
\hline & 0,25 & "Para quem quer saber da história da região e sobre a construção da represa. Bem estruturado, interessante." \\
\hline & 0,00 & $\begin{array}{l}\text { "Museu pequeno que conta a história da construção de Itaipu. Fizemos na volta da usina e o ingresso está incluído } \\
\text { na visita a Itaipu." }\end{array}$ \\
\hline & $-0,25$ & $\begin{array}{l}\text { "Fomos visitar o Ecomuseu e infelizmente a metade dele estava fechada para reforma pois iriam receber uma } \\
\text { exposição do Sebastião Salgado, mas mesmo assim valeu a pena, conta toda a história da construção da } \\
\text { barragem." }\end{array}$ \\
\hline & $-0,50$ & $\begin{array}{l}\text { "Apresenta objetos e animais resgatados durante a construção da usina. Muitas informações sobre as fases da } \\
\text { construção. Acervo rico. Porém, os objetos apresentados não possuem informações de identificação. Para um } \\
\text { museu é uma falha grave." }\end{array}$ \\
\hline & $-0,75$ & $\begin{array}{l}\text { "Como é um museu, não é uma visita muito agitada. Porém eu achei teria mais interatividade, o que acontece } \\
\text { apenas em uma das salas. Mas conta toda a história de Foz, e de Itaipu." }\end{array}$ \\
\hline \multirow{7}{*}{ 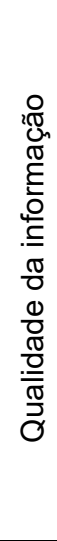 } & 0,75 & "Bom passeio para família e instrução. Bem explicativo e fácil de fazer sem guia, muito interessante. Gostei muito." \\
\hline & 0,50 & $\begin{array}{l}\text { "Lugar onde podemos conhecer um pouco da história de Itaipu, muito interessante, onde encontramos várias } \\
\text { maquetes de Itaipu, do território, e muitos objetos da época de construção da usina!!!!" }\end{array}$ \\
\hline & 0,25 & $\begin{array}{l}\text { "Reserve pelo menos } 1 \text { hora para conhecer o Ecomuseu, tem muita coisa para ver. Algumas portas parecem } \\
\text { fechadas, mas quando vc se aproxima elas abrem e reservam boas surpresas." }\end{array}$ \\
\hline & 0,00 & "Conhecer a história da região e conhecer como foi construída a usina é um complemento ao passeio da usina." \\
\hline & $-0,25$ & $\begin{array}{l}\text { "Infelizmente não tivemos a oportunidade de conhecer essa atração pois ela estava fechada devido a greve dos } \\
\text { funcionários de Itaipu." }\end{array}$ \\
\hline & $-0,50$ & $\begin{array}{l}\text { "A história da hidrelétrica em um só lugar. Toda o cronograma da construção, com cada etapa e uma maquete } \\
\text { gigante de toda a região abrangida pelo rio. Entretanto parecia um pouco abandonado." }\end{array}$ \\
\hline & $-0,75$ & $\begin{array}{l}\text { "Não sei se as minhas expectativas é que estavam altas... rs Mas achei fraquinho. Vale a visita para quem já está ali } \\
\text { fazendo outros passeios na usina da Itaipu, principalmente porque o ingresso é baratinho (até março está gratuito). } \\
\text { Conta um pouquinho da história da construção da usina." }\end{array}$ \\
\hline \multirow{6}{*}{ 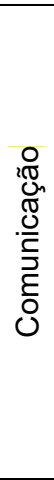 } & 0,75 & $\begin{array}{l}\text { "Gostei bastante do Ecomuseu, com ferramental da época dos imigrantes, bem como arquivos e ferramentas da } \\
\text { construção da usina." }\end{array}$ \\
\hline & 0,50 & $\begin{array}{l}\text { "Muito bom. Conta a história e como funciona a usina hidrelétrica de Itaipu. Traz muitas curiosidades, vale a pena a } \\
\text { visita." }\end{array}$ \\
\hline & 0,25 & $\begin{array}{l}\text { "ajuda a esclarecer as dúvidas e ter a real noção de como começou a formação da Itaipu super. recomendamos o } \\
\text { passeio" }\end{array}$ \\
\hline & 0,00 & "Mostra como foi realizada a construção de Itaipu. Tem fotos históricas, maquetes, ferramentas e exposições" \\
\hline & $-0,25$ & $\begin{array}{l}\text { "Tem informações importantes sobre a fauna, flora, história e geografia da região. Faltou mais criticidade ao } \\
\text { apresentar tais informações, como falar sobre o impacto ambiental irreversível da usina de Itaipu; a formação da } \\
\text { cidade as custas da espoliação dos nativos, etc." }\end{array}$ \\
\hline & $-0,50$ & $\begin{array}{l}\text { "Penso que tenho "ido com muita sede ao pote", como se diz. Esperava encontrar mais coisas detalhadas e essa } \\
\text { ausência me deixou um pouco frustrada." }\end{array}$ \\
\hline \multirow{6}{*}{ 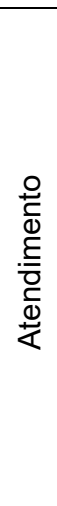 } & 0,75 & $\begin{array}{l}\text { "Meu filho adorou este local visitado nas férias. Guias do local, muito bem treinados e simpáticos. Vale a pena } \\
\text { visitar." }\end{array}$ \\
\hline & 0,50 & "Museu muito interessante e bem cuidado. Monitores atenciosos. Preço justo. A maquete de vidro é muito legal." \\
\hline & 0,25 & "Bom para saber sobre a história da usina, bastante informativo e interessante, guias que conhecem o lugar." \\
\hline & 0,00 & $\begin{array}{l}\text { "Lugar aconchegante e conta a história da barragem. Procure saber se há guia disponível. Chegamos após a saída } \\
\text { de um tour guiado e nos sentimos abandonados..." }\end{array}$ \\
\hline & $-0,25$ & $\begin{array}{l}\text { "Esperava bem mais do museu. As pessoas fazem a visitação sozinha, sem monitores para acompanhar. É dividido } \\
\text { em salas. Em meia hora se consegue fazer a visita. É cobrado o valor de } \mathrm{R} \$ 10,00 \text {, mas não vale. Deveria ser } \\
\text { gratuito por não oferecer nada demais." }\end{array}$ \\
\hline & $-0,50$ & $\begin{array}{l}\text { O museu tem diversas pequenas alas onde guardam diferentes exposições, desde artistas, a representação de } \\
\text { atividades de homens pré-históricos, passando a maquetes sobre a usina, e animais da região. Falta guia na } \\
\text { visitação, o que poderia melhorar a experiência. }\end{array}$ \\
\hline
\end{tabular}

Fonte: elaborado pelos autores 
Nos comentários com sentimento positivo, nota-se a incidência de palavras e/ou termos como "excelente", "gostei" e "interessante", enfatizando as maquetes, as informações disponíveis e a riqueza histórica do Ecomuseu. No outro polo, os termos mais comuns refletem uma expectativa não atendida, retratando casos em que os visitantes se sentiram mal assistidos ou consideraram que o local não estava preparado para recebê-los, apresentando falhas de serviço. É importante salientar que tais aspectos são consequentes da qualidade do serviço. Por isso, é importante mantê-la em níveis elevados para o cliente, como apontado por Wirtz e Lovelock (2018).

Os comentários neutros são caracterizados pela sensação de que se trata de uma visita comum, sem muitos altos e baixos, em que se preza por um comentário mais descritivo sobre a atração (e. g. "Mostra como foi realizada a construção de Itaipu. Tem fotos históricas, maquetes, ferramentas e exposições").

É interessante que a gestão invista em aspectos que tornem o sentimento do visitante positivo, tendo em vista a importância dos relatos da experiência de clientes que já passaram pela experiência do serviço como condutores da intenção de visita por parte de novos clientes, conforme salientado por Ayeh, Au e Law (2013).

A última análise realizada foi a de clusters, resumida na Figura 3. A análise foi feita com a elaboração de três tipos de agrupamentos: com dois, três e quatro clusters.

Figura 3 - Análise de clusters

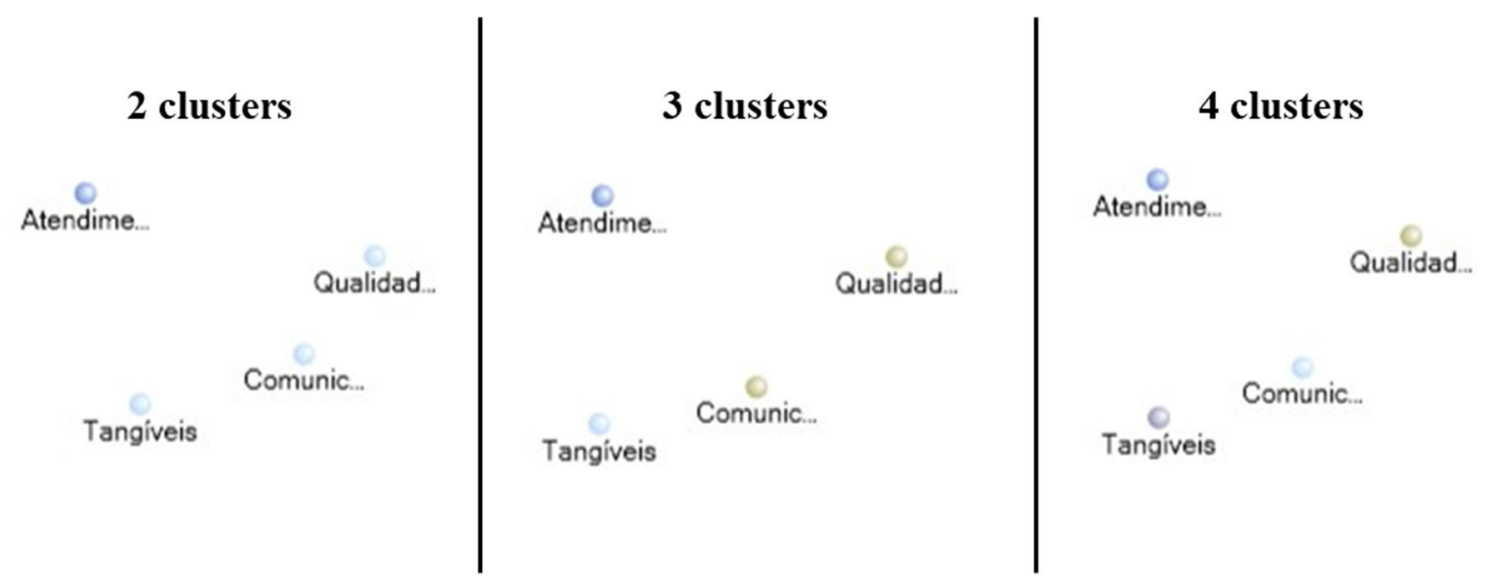

Fonte: saída do software NVivo

$\mathrm{Na}$ análise com dois clusters, verificou-se que as dimensões tangíveis, comunicação e qualidade da informação tiveram maior correlação, enquanto a dimensão atendimento se diferenciou das demais. Com três clusters, as dimensões de qualidade da informação e comunicação se agruparam, enquanto os outros dois foram formados, individualmente, pelas dimensões tangíveis e atendimento. Com quatro clusters, observou-se que, de fato, as dimensões são heterogêneas, obtendo-se coeficientes de correlação próximos de zero. Assim, considera-se que a codificação realizada foi propícia para a análise do fenômeno por meio das dimensões da qualidade de serviços em museus. 


\section{CONSIDERAÇÕES FINAIS}

Este trabalho objetivou analisar os comentários inseridos pelos visitantes do Ecomuseu de Itaipu no site TripAdvisor, considerando as quatro dimensões da qualidade de serviços em museu: tangíveis, qualidade da informação, comunicação e atendimento. Foram realizadas uma análise e a categorização de 1056 comentários publicados no site de viagens. Os comentários foram codificados de acordo com palavras que refletiam cada uma das dimensões da qualidade.

Percebeu-se com as análises que as dimensões mais mencionadas pelo visitante do Ecomuseu de Itaipu foram as de aspectos tangíveis (61\%) e qualidade da informação (52\%). E ainda, o sentimento positivo nos comentários se fez mais presente e prevaleceu em todas as dimensões analisadas. A dimensão de atendimento foi a que teve mais comentários positivos e menos comentários negativos, evidenciando a satisfação dos usuários com a atenção dispensada pelos funcionários, guias ou monitores do Ecomuseu. Quanto à análise de clusters, evidenciou-se, na análise com quatro agrupamentos, que as correlações entre as dimensões ficaram próximas de zero, o que demonstra que a codificação realizada teve sucesso ao delimitar o que cada dimensão deveria medir.

Gerencialmente, o artigo contribuiu para a gestão do Ecomuseu. A predominância da dimensão dos elementos tangíveis evidencia a necessidade de se dar atenção contínua a estratégias de marketing para tangibilizar os elementos da prestação do serviço para os visitantes. A análise de sentimento realizada também proveu informações importantes para se entender as sensações dos visitantes, permitindo a atuação da gestão para incorporar elementos que causem mais impacto positivo na experiência da visita.

Tecnicamente, a combinação da metodologia de análise de conteúdo por meio da contagem de palavras, seguida pela análise de sentimento permitiu analisar de maneira menos limitada, mesmo em uma grande quantidade de observações. Assim, além de verificar a frequência de palavras em cada dimensão, foi possível aprofundar na análise, identificando qual parcela dessa frequência era positiva, neutra ou negativa.

Como limitação do estudo, ressalta-se que a análise, embora tenha considerado todos os comentários, não se voltou para a verificação de tendências em períodos específicos ao longo do tempo. Assim, sugere-se que, em pesquisas futuras, sejam levantadas tendências nos comentários, identificando a evolução da frequência das dimensões da qualidade, bem como a evolução da análise de sentimento.

\section{REFERÊNCIAS}

ALBU, R.-G. The importance of the quality of environmental factors on tourism products. An application of the kano model. Bulletin of the Transilvania University of Brasov. Economic Sciences. Series V, v. 2, p. 127, 2009.

ALCARAZ, C.; HUME, M.; MORT, G. S. Creating sustainable practice in a museum context: Adopting service-centricity in non-profit museums. Australasian Marketing Journal (AMJ), v. 17, n. 4, p. 219-225, 2009.

AYEH, J. K.; AU, N.; LAW, R. "Do we believe in TripAdvisor?" Examining credibility perceptions and online travelers' attitude toward using user-generated content. Journal of Travel Research, v. 52, n. 4, p. 437-452, 2013.

BARDIN, L. Análise de conteúdo. São Paulo: Edições 70, 2011.

FALK, J. H.; DIERKING, L. D. The museum experience revisited. Routledge, 2016.

FOTIS, J N.; BUHALIS, D.; ROSSIDES, N. Social media use and impact during the holiday travel planning process. Springer-Verlag, 2012.

FROCHOT, I.; HUGHES, H. HISTOQUAL: The development of a historic houses assessment scale. Tourism management, v. 21, n. 2, p. 157-167, 2000.

GODOY, A. S. Introdução à pesquisa qualitativa e suas possibilidades. Revista de administração de empresas, v. 35, n. 2, p. 57-63, 1995. 
GONÇALVES, P. et al. Comparing and combining sentiment analysis methods. In: Proceedings of the first ACM conference on Online social networks. ACM, 2013. p. 27-38.

GOSLING, M. et al. Avaliando a Qualidade de Serviços em Museu: Validação e Teste de Escala/Evaluating Museum Service Quality: A Scale Validation and Test. ROSA DOS VENTOS-Turismo e Hospitalidade, v. 8, n. 2, 2016.

HENNIG-THURAU, T. et al. Electronic word-of-mouth via consumer-opinion platforms: what motivates consumers to articulate themselves on the internet? Journal of interactive marketing, v. 18, n. 1, p. 38-52, 2004.

KRUMM, J.; DAVIES, N.; NARAYANASWAMI, C. User-generated content. IEEE Pervasive Computing, v. 7, n. 4, p. $10-11,2008$.

MENDONÇA, F. Modelo de antecedentes da satisfação, da comunicação boca-a-boca e da aprendizagem em museus: um estudo empírico no espaço TIM UFMG do Conhecimento. 2012. Dissertação. Mestrado em Administração, Universidade FUMEC, Belo Horizonte.

MIGUEL, M. C.; FREIRE, V. F. Avaliação da qualidade orientada ao usuário do museu capixaba do negro: aplicação da abordagem teórico-metodológica Servqual em um espaço museológico de vitória-es. Revista Guará, v. 1, n. 5, 2016.

MONDO, T. S.; DA SILVA, F. V. C.; MARTINS, A. I. QUALIDADE DE SERVIÇOS EM MUSEUS: A PERCEPÇÃO DOS VISITANTES DO MUSEU HISTÓRICO DE SANTA CATARINA. Revista Eletrônica de Administração e Turismo-ReAT, v. 8, n. 4, p. 890-909, 2016.

O'CONNOR, P. Managing a hotel's image on TripAdvisor. Journal of Hospitality Marketing \& Management, v. 19, n. 7, p. 754-772, 2010.

PARASURAMAN, A.; ZEITHAML, V. A.; BERRY, L. L. Servqual: A multiple-item scale for measuring consumer perc. Journal of retailing, v. 64, n. 1, p. $12,1988$.

PIOVESAN, A.; TEMPORINI, E. R. Pesquisa exploratória: procedimento metodológico para o estudo de fatores humanos no campo da saúde pública. Revista de Saúde Pública, v. 29, p. 318-325, 1995.

RICHARDS, G. ATLAS Cultural Tourism Survey-summary report. ATLAS Cultural Tourism Project: Association for Tourism and Leisure Education, 2007.

ROSALEM, V. Análise das percepções dos principais atores da cadeia produtiva da saúde sobre a qualidade dos serviços prestados por hospitais no Estado de Goiás-Br. 2013. Tese. Doutorado em Administração, Fundação Getúlio Vargas, São Paulo.

SU, Y.; TENG, W. Contemplating museums' service failure: Extracting the service quality dimensions of museums from negative on-line reviews. Tourism Management, v. 69, p. 214-222, 2018.

TAX, S. S.; BROWN, S. W. Recovering and learning from service failure. MIT Sloan Management Review, v. 40, n. 1, p. $75,1998$.

TUNG, V. W. S.; RITCHIE, JR B. Investigating the memorable experiences of the senior travel market: An examination of the reminiscence bump. Journal of Travel \& Tourism Marketing, v. 28, n. 3, p. 331-343, 2011.

WIRTZ, J.; LOVELOCK, C. Essentials of Services Marketing. 3rd ed. Harlow: Pearson Education Limited, 2018.

XAVIER, I. da F. O uso contínuo do conteúdo gerado pelo usuário na escolha de um destino turístico: um estudo longitudinal. 2018. Trabalho de Conclusão de Curso. Universidade Federal do Rio Grande do Norte.

ZEITHAML, V.; BITNER, M.; GREMLER, D. Marketing de Serviços: A Empresa com Foco no Cliente. Porto Alegre: AMGH Editora, 2014. 